\title{
The Protective Properties of Thin Alumina Films Deposited by Metal Organic Chemical Vapour Deposition against High-temperature Corrosion of Stainless Steels*
}

\author{
R. W. J. MORSSINKHOF, T. FRANSEN, M. M. D. HEUSINKVELD and P. J. GELLINGS \\ Laboratory of Inorganic Chemistry, Materials Science and Catalysis, University of Twente, P.O. Box 217, 7500 AE Enschede \\ (The Netherlands)
}

(Received March 2, 1989)

\begin{abstract}
Coatings of $\mathrm{Al}_{2} \mathrm{O}_{3}$ were deposited on Incoloy $800 \mathrm{H}$ and AISI 304 by means of metal organic chemical vapour deposition. Diffusion limitation was the rate-determining step above $420^{\circ} \mathrm{C}$. Below this temperature, the activation energy of the reaction appeared to be $30 \mathrm{~kJ} \mathrm{~mol}^{-1}$. Coating with $\mathrm{Al}_{2} \mathrm{O}_{3}$ increases the sulphidation resistance by at least 4-10 times. The sulphidation resistance is influenced by the growth rate of the coating and by the thermomechanical properties of the coatingsubstrate combination. The sulphidation resistance also depends on the growth rate of the coating. The weight gain of coated specimens is about 10-14 times less than that of uncoated specimens. Treatment of the coated samples in air at $850^{\circ} \mathrm{C}$ results in a still higher sulphidation resistance. This is due to the chromium oxide grown into the cracks in the coating during the treatment. These cracks are the result of mechanical stresses at irregularities.
\end{abstract}

\section{Introduction}

Stainless steels with a reasonable resistance to oxidizing environments are available, but no steels are available with an acceptable resistance to corrosion in sulphidizing environments at high temperatures. There is a large demand for materials that can be used in these atmospheres because there is an increasing tendency to use fossil fuels, such as coal, which contain sulphur.

There are different ways to find a solution for this problem. Some ceramic materials exhibit a good resistance to oxidation and sulphidation, but

\footnotetext{
*Invited paper.
}

cannot be used due to fabrication requirements and/or their mechanical properties. A combination of the good properties of ceramics and the mechanical strength of metals might, however, lead to a solution. Two methods to achieve such a combination are as follows:

(1) chemical modification of the "natural" oxide of the alloy to be protected;

(2) the application of a different type of oxide on the clean or oxidized metal.

Modification of the "natural" oxide may be realized by ion implantation of yttrium and/or cerium for instance $[1,2]$ and by the sol-gel method [3] and may result in a reasonably good protection against sulphidation. The direct application of a different oxide for protective purposes was carried out by Bennett [4] who applied the chemical vapour deposition (CVD) technique for the coating of several stainless steels with $\mathrm{SiO}_{2}$. After treatment in argon this coating provides a good protection to sulphidation up to $900{ }^{\circ} \mathrm{C}$. Above this temperature it cracks because of recrystallization of the $\mathrm{SiO}_{2}$ layer.

Recently two processes have been developed to produce thin $\mathrm{Al}_{2} \mathrm{O}_{3}$ films directly, and both are used in the electronic component industries. In the first process $\mathrm{AlCl}_{3}$ and water or $\mathrm{CO}_{2}-\mathrm{H}_{2}$ are used to form $\mathrm{Al}_{2} \mathrm{O}_{3}$ at $1000-1200{ }^{\circ} \mathrm{C}$ and at a pressure of $0.5-5$ Torr $[5,6]$. The second process has been described by Aboaf [7]. He used aluminium triisopropoxide ( $\mathrm{ATI}$ ), to form a dense $\mathrm{Al}_{2} \mathrm{O}_{3}$ film at $420^{\circ} \mathrm{C}$ at atmospheric pressure.

The process by Aboaf was used to form thin layers on stainless steel, but not for the protection against corrosion at high temperatures. Aluminium oxide-forming alloys are nevertheless well known to provide a good protection against many 
types of corrosion. For this reason, Aboaf's process was reconsidered as a starting point for forming thin alumina layers on stainless steel. To optimize the protective properties of the layers produced, the process parameters were varied on the basic of a simple theoretical consideration. The results are presented in this paper.

\section{Theoretical considerations}

For a good understanding of the influence of the process parameters on the final quality of a coating, it is necessary to develop a model. Very complicated models for CVD systems have been developed [8] but the practical usefulness of these models is limited because they require detailed information of the process kinetics and this is rarely available.

A simple model that can be used for a basic understanding of a CVD process was set up by Bird et al. [9] and is known as a "film model". This model results in two extreme situations for the growth rate determining step:

$k_{\mathrm{r}} / k_{\mathrm{g}} \gg 1$

In this situation the growth rate is determined by the gas phase mass transfer coefficient, and this situation is called diffusion-limited growth.

$k_{\mathrm{r}} / k_{\mathrm{g}} \ll 1$

This situation is the opposite and refers to reaction rate-limited growth.

The ratio $k_{\mathrm{r}} / k_{\mathrm{g}}$ (where $k_{\mathrm{r}}$ is the reaction rate constant and $k_{\mathrm{g}}$ is the gas phase transfer coefficient) is called the Sherwood number (Sh) (van der Brekel [10] refers to it as the CVD number) and is an important factor because it influences the quality of the coating. If a scratch is present on the surface to be coated, the coating starts to grow on the whole surface but after a certain time the entrance of the scratch becomes smaller if $\mathrm{Sh} \gg 1$. This is because the reaction is very fast; thus the reactive compound is deposited at the entrance, and will at last close the scratch without filling the pore. This means that a porous coating is produced on damaged places on the surface.

The Sherwood number may also influence the homogeneity of the coating for $\mathrm{Sh} \gg 1$ because this leads to a concentration gradient of the reactive compound along the substrate. Thus, in order to obtain good corrosion properties, the deposition should be controlled by the reaction rate.

\section{Experimental details}

\subsection{The deposition of $\mathrm{Al}_{2} \mathrm{O}_{3}$}

The $\mathrm{Al}_{2} \mathrm{O}_{3}$ films were produced by decomposing ATI (Merck art. 801079, purity greater than $98 \%$, melting point $134-137^{\circ} \mathrm{C}$ ). This was melted in a bubbler heated by a silicon oil bath to saturate a nitrogen gas flow which was diluted to obtain the desired gas-phase concentration. The resulting flow was led into a vertical furnace. In this furnace, the substrate specimens were attached to a ceramic tube with a thermocouple at the inside to measure the substrate temperature and regulate the furnace. This tube was moved up or down to change the substrate position (Fig. 1).

The standard conditions were a substrate temperature of $420^{\circ} \mathrm{C}$, a saturation temperature of $134^{\circ} \mathrm{C}$, a carrier gas flow of $31 \mathrm{~min}^{-1}$ and a diluent gas flow of $71 \mathrm{~min}^{-1}$. The substrates were placed in the middle of the furnace.

The coatings were investigated by means of optical microscopy and scanning electron microscopy and their thicknesses were determined by weighing.

\subsection{Materials}

AISI 304 and Incoloy $800 \mathrm{H}$ were used as the substrates. Incoloy $800 \mathrm{H}$ was annealed for $1 \mathrm{~h}$ at $1373 \mathrm{~K}$, water quenched, annealed for $1 \mathrm{~h}$ at $1223 \mathrm{~K}$ and water quenched again. Pieces $(1 \mathrm{~mm}$ thick, $12 \mathrm{~mm}$ diameter) were cut from a rod and the surface finish was performed by grinding with carborundum paper, and by finally polishing with $0.05 \mu \mathrm{m} \mathrm{Al}{ }_{2} \mathrm{O}_{3}$ powder. The AISI 304 specimens

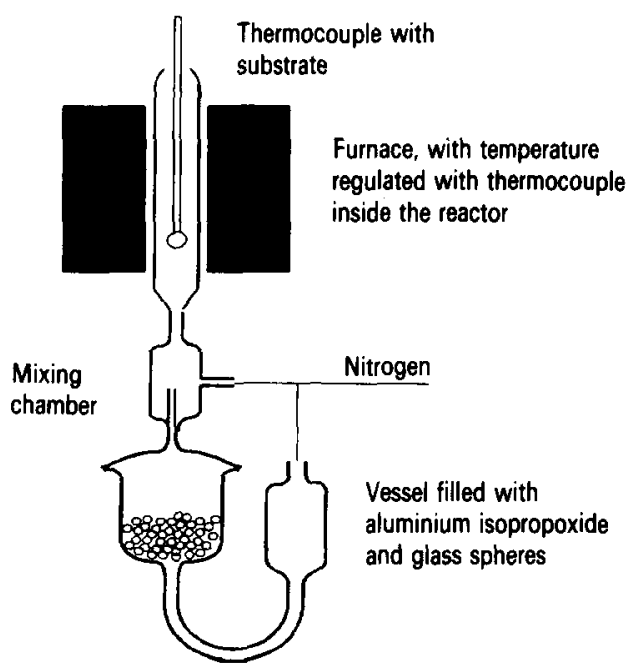

Fig. 1. Schematic diagram of experimental apparatus. 
were cut from an electropolished metal sheet. Both types of specimen were ultrasonically cleaned with hexane and ethanol prior to coating.

\subsection{Oxidation and sulphidation experiments}

Static oxidation tests were carried out in air in a furnace heated to $850^{\circ} \mathrm{C}$ at a rate of $2{ }^{\circ} \mathrm{C} \mathrm{min}^{-1}$, kept at $850{ }^{\circ} \mathrm{C}$ for $24 \mathrm{~h}$ and cooled at $0.5^{\circ} \mathrm{C} \mathrm{min}-1$ to prevent spalling. Thermogravimetric oxidation tests were carried out in a Setaram electrical thermobalance in air for $96 \mathrm{~h}$.

Sulphidation experiments were carried out in a closed system. This was first evacuated and flushed with argon for $16 \mathrm{~h}$ followed by flushing with $1 \% \mathrm{H}_{2} \mathrm{~S}, 19 \% \mathrm{H}_{2}$ and $80 \% \mathrm{Ar}$ for $4 \mathrm{~h}$. The system was then closed and heated to $600{ }^{\circ} \mathrm{C}$. The resulting $P_{\mathrm{O}_{2}}$ was $10^{-32} \mathrm{~atm}$ and $P_{\mathrm{S}_{2}}$ was $10^{-9} \mathrm{~atm}$.

\section{Results and discussion}

\subsection{Deposition experiments}

In general, the surfaces of the deposited layers were very smooth. In the first experiments interference rings were observed, indicative of inhomogeneous coating thicknesses along the substrate. $\mathrm{X}$-ray diffraction showed that the coating was virtually amorphous, and with transmission electron microscopy very small crystals could only be detected on some isolated places.

A set of deposition experiments was carried out in order to study the effect of different process parameters. Changing the deposition time results in a linear relationship of the coating thickness with time and in a growth rate of $2.4 \mu \mathrm{m} \mathrm{h}^{-1}$. Aboaf [7] also found a linear relationship, but the growth rate was substantially lower.

Varying the total flow resulted in a coating thickness proportional to the square root of the flow rate, indicative of a mass transfer-limited growth rate, i.e. Sh $\gg 1$ (Fig. 2).

As discussed above, Sh should be less than unity in order to obtain good coatings. In order to go from $\mathrm{Sh} \gg 1$ to $\mathrm{Sh} \ll 1$, several parameters, such as the gas-phase concentration and the substrate temperature, can be changed. The results of the experiments with varying temperature are shown in an Arrhenius plot (Fig. 3). The activation energy changes around $420^{\circ} \mathrm{C}$. Above this temperature it is $7 \mathrm{~kJ} \mathrm{~mol}^{-1}$, indicative of gasphase diffusion limitation, whereas below this temperature its value is about $30 \mathrm{~kJ} \mathrm{~mol}^{-1}$. This difference in activation energy above and below

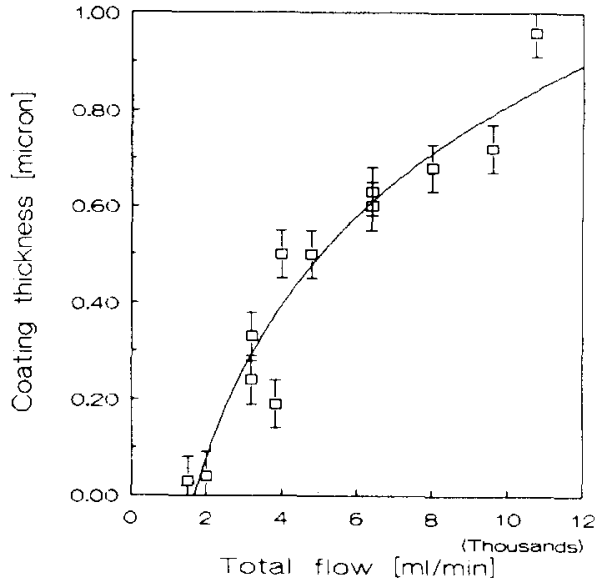

Fig. 2. Coating thickness $(\mu \mathrm{m})$ as a function of the total flow $\left(\mathrm{ml} \mathrm{min}^{-1}\right)$ : $($ coating thickness $)=(\text { total flow })^{0.45 \pm 0.05}$.

$420^{\circ} \mathrm{C}$ may thus very well indicate a change of the rate-determining step: below this temperature the kinetics is governed by the reaction rate, and at higher temperatures gas-phase diffusion is ratedetermining. The effect of the deposition regime can also be seen in Figs. 4 and 5, showing the enormous influence on the morphology of the coating. Thus, to obtain good coatings ( $\mathrm{Sh} \ll 1$ ), the temperature should not be higher than $420^{\circ} \mathrm{C}$. In order to preserve a sufficiently high deposition rate and to avoid any gas-diffusion limitation, a temperature between 400 and $420^{\circ} \mathrm{C}$ was considered to be satisfactory.

Changing the regime without reduction of the growth rate by reducing the temperature can be

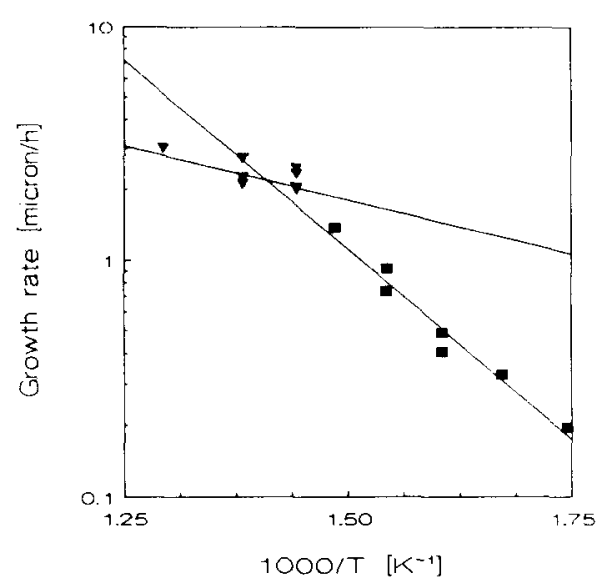

Fig. 3. Growth rate $\left(\mu \mathrm{m} \mathrm{h}^{-1}\right)$ as a function of temperature $(\mathbf{K})$ in an Arrhenius plot: $\mathbf{D}$, reaction limited; $\boldsymbol{\nabla}$, diffusion limited. $E_{\mathrm{a}}$ for diffusion is $7 \mathrm{~kJ} \mathrm{~mol}^{-1}$ and $E_{\mathrm{a}}$ for reaction is $30 \mathrm{~kJ} \mathrm{~mol}^{-1}$. 


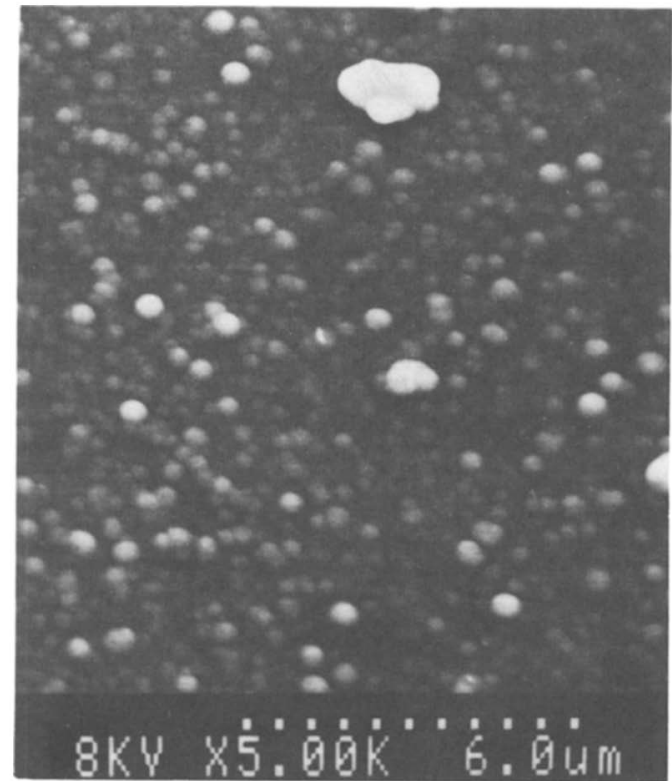

Fig. 4. Scanning electron micrograph of a coating deposited at $450{ }^{\circ} \mathrm{C}$.

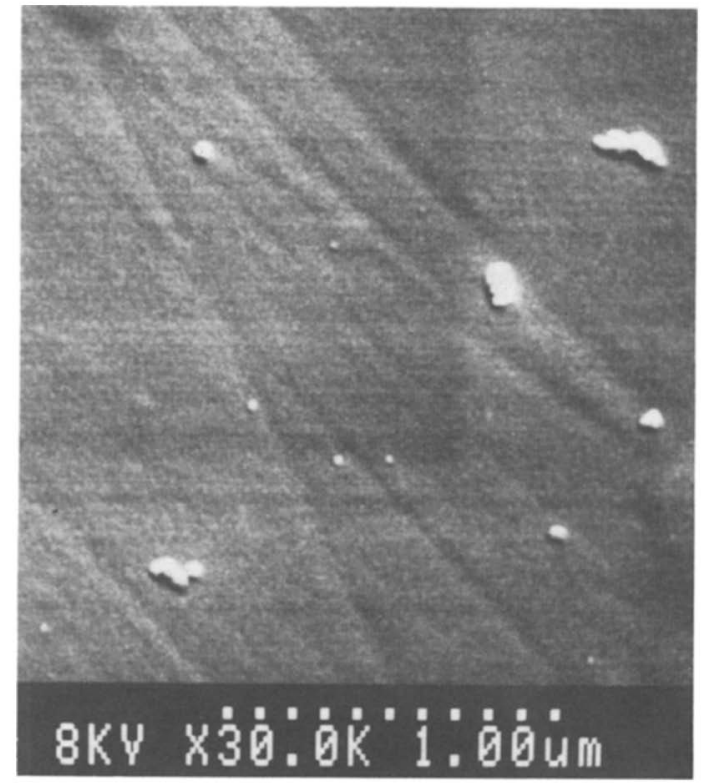

Fig. 5. Scanning electron micrograph of a coating deposited at $350^{\circ} \mathrm{C}$.

realized by increasing the temperature difference between the gas phase and the substrate surface or increasing the effective gas-phase concentration. The first possibility can be obtained by changing the temperature difference between the substrate and the furnace wall. The change in temperature difference results in an increasing effective diffusion coefficient [11], leading to an increasing growth rate. This can be obtained by changing the substrate position from the centre to the entrance of the furnace, because the wall temperature necessary to obtain a substrate temperature of $420^{\circ} \mathrm{C}$ at the centre is $100^{\circ} \mathrm{C}$ less than at the entrance.

The effective gas concentration cannot be changed easily by changing the saturation temperature because the rate of reaction in the gas phase will increase and more powder will be formed. But changing the position of the substrate also results in an increasing gas-phase concentration because less time is available for the homogeneous gasphase reaction. Thus near the entrance the effective gas-phase concentration and the temperature difference are as high as possible. The new position indeed results in a change of the kinetic regime from $S h \gg 1$ to $S h \ll 1$, since the uniformity of the coating is much better and decreases with increasing distance from the entrance. Coatings made at $4 \mathrm{~cm}$ from the entrance show no interference rings and different colours are only observed at the edges of the specimen, while at the other side of the furnace extreme differences in coating thickness are observed.

\section{Corrosion properties}

Substrate samples were coated with a $0.4 \pm 0.1 \mu \mathrm{m} \mathrm{Al}_{2} \mathrm{O}_{3}$ film. To investigate the effect of the thickness of the coating the deposition time was changed, and to investigate the effect of the growth rate on the corrosion properties the saturation temperature was changed while the deposition time was adjusted to produce the same layer thickness on different specimens. The standard parameters were used to cover the Incoloy $800 \mathrm{H}$ samples.

An improvement factor, defined as the weight gain of a coated sample divided by the weight gain of an uncoated sample, is used to judge the quality of the coating.

\subsection{Oxidation}

Examination of the oxidized samples by optical microscopy and scanning electron microscopy (SEM) showed that oxidation can cause cracks in the coating (Fig. 6) especially at irregularities on the substrate. These cracks are induced by (thermo)mechanical stresses and are the main reason for the weight gain of a specimen by oxidation because, particularly at these places, the under- 


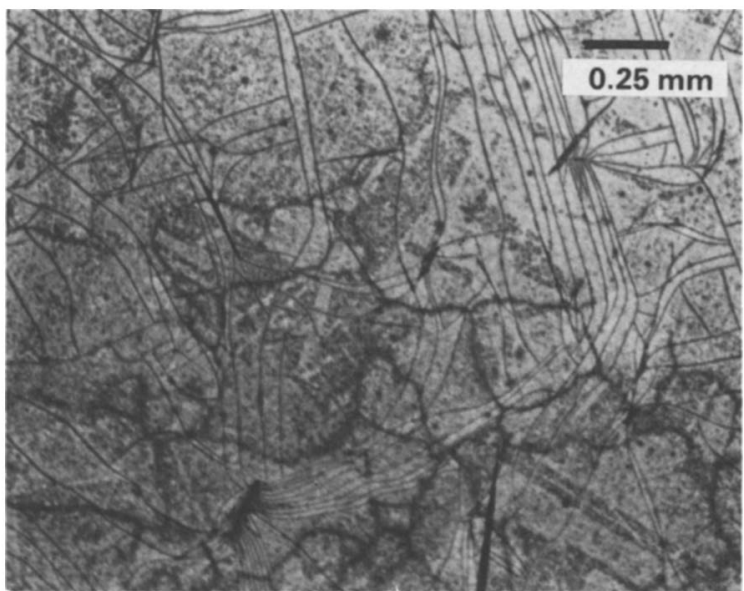

Fig. 6. A coated sample $(0.4 \mu \mathrm{m})$ oxidized at $850{ }^{\circ} \mathrm{C}$ showing cracks due to mechanical stresses, and oxidized areas at the grain boundaries.

laying substrate is oxidized. In Fig. 7 another phenomenon caused by oxidation is shown. It seems that the grain boundaries of the substrate are preferentially oxidized, but these specimens nevertheless showed only very small weight gains, and SEM only showed a little extra roughness at the grain boundaries.

Thermogravimetric experiments show that the oxidation resistance is increased about 5-10 times. Factors influencing the corrosion resistance of the coating are the thickness and the growth rate but these two can be changed in different ways (gasphase concentration, position in the furnace and deposition temperature) resulting in the same layer thickness or growth rate. This may cause

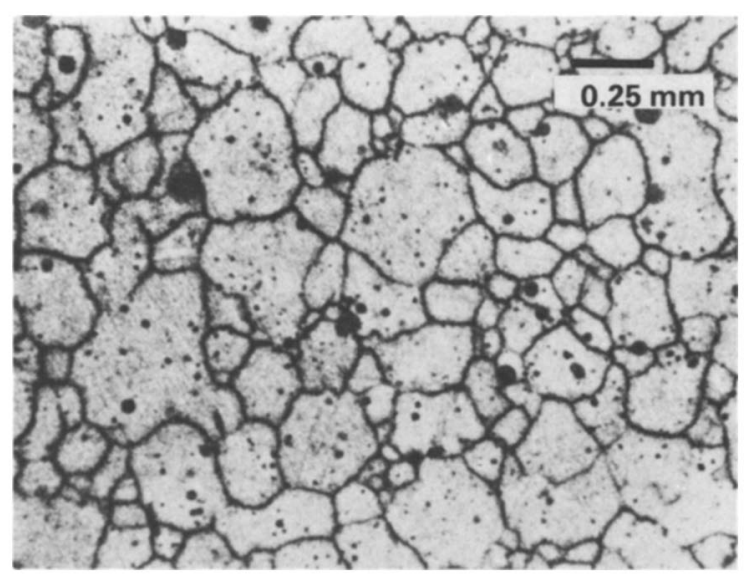

Fig. 7. A coated sample $(0.2 \mu \mathrm{m})$ oxidized at $850^{\circ} \mathrm{C}$ showing no cracks but oxidized areas at the grain boundaries.

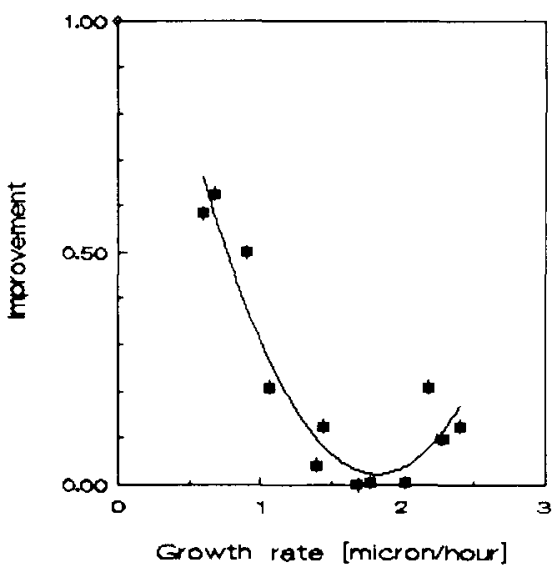

Fig. 8. Improvement as a function of the growth rate $\left(\mu \mathrm{m} \mathrm{h}^{-1}\right)$ after $24 \mathrm{~h}$ oxidation in air.

scattering of the results because it is very difficult to modify only one parameter.

A comparison of Figs. 6 and 7 shows the effect of the coating thickness. A thick coating is more sensitive to thermomechanical stresses. Due to these stresses, cracks occur at irregularities on the substrate. The relation between the coating thickness and the sensitivity for (thermo)mechanical stresses is an object of a further study.

Figure 8 shows that the growth rate has an effect on the oxidation resistance, meaning that the growth rate also has an important effect on the quality of the coating. Large growth rates yield coatings with many imperfections, resulting in a decreasing oxidation resistance. These imperfections are probably caused by $\mathrm{Al}_{2} \mathrm{O}_{3}$ particles formed by the homogeneous gas-phase reaction. These particles can adhere to the substrate and be covered with "normal" coating material. This homogeneous reaction is faster when the concentration is higher since it is a first-order reaction. The decrease of the resistance to oxidation with smaller growth rate cannot be explained at this moment.

\subsection{Sulphidation}

The growth rate and the layer thickness are important. The previously mentioned cracks result in a relatively large weight gain due to heavy, localized attack. The sulphidation resistance is improved by a factor of 5-10 times even when imperfections are present in the coating.

In Fig. 9, the effect of the growth rate on the resistance to sulphidation is shown. Slowly grown layers have the best sulphidation resistance but all 


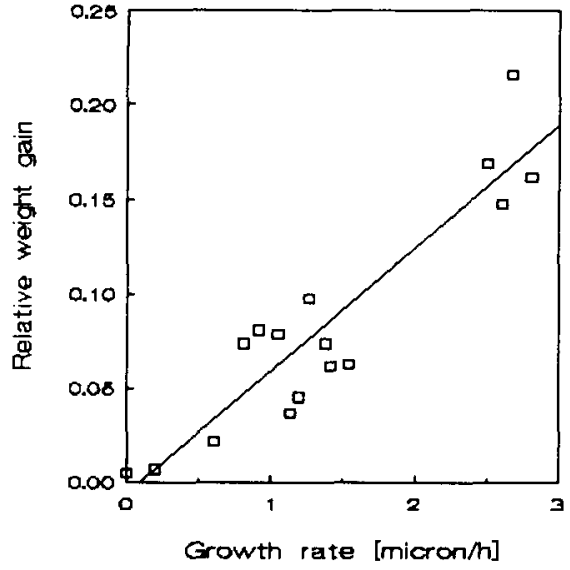

Fig. 9. Improvement as a function of the growth rate $\left(\mu \mathrm{m} \mathrm{h}^{-1}\right)$ after $100 \mathrm{~h}$ sulphidation at $600^{\circ} \mathrm{C}$, in $\mathrm{H}_{2}-\mathrm{H}_{2} \mathrm{~S}$.

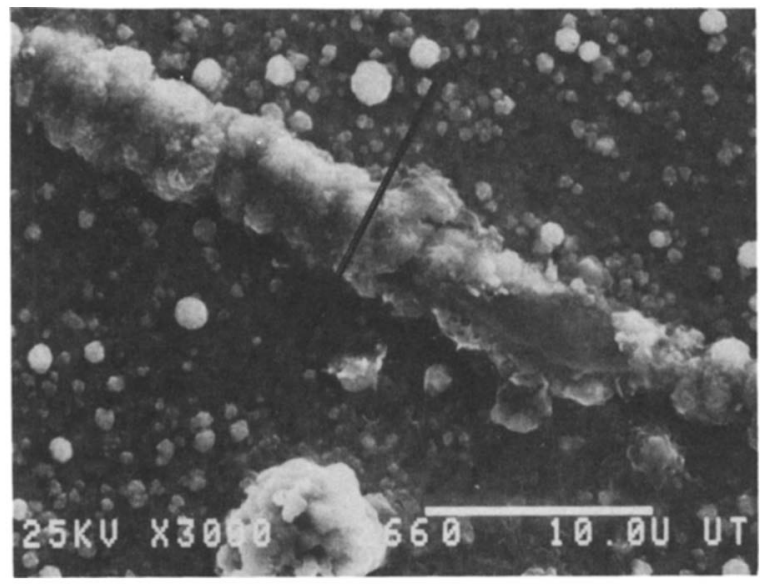

Fig. 10. Scanning electron micrograph of treated and sulphidized sample $\left(200 \mathrm{~h}\right.$ at $550^{\circ} \mathrm{C}$ in $\mathrm{H}_{2}-\mathrm{H}_{2} \mathrm{~S}$ ).

layers lead to at least a 5 times better overall resistance to sulphidation than the uncoated samples. The effect of the growth rate in this case is also caused by imperfections built in during the deposition of the coating. The scattering of the sulphidation resistance is probably caused by these inhomogeneities and by cracks at sharp edges or the support hole of the specimens because at these places the thermomechanical stresses are relatively high.

Since the oxidation experiments indicated that the cracks are filled with $\mathrm{Cr}_{2} \mathrm{O}_{3}$ during the oxidation, some specimens were treated prior to the sulphidation in a furnace for $16 \mathrm{~h}$ at $850^{\circ} \mathrm{C}$ in air. The results in Table 1 reveal that this treatment increases the sulphidation resistance significantly.

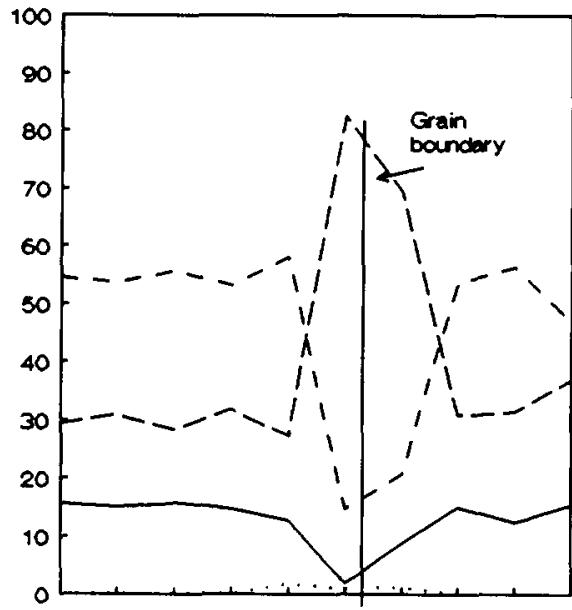

Fig. 11. Energy-dispersive X-ray linescan of feature at Fig. 10 along the marked position: - $-\ldots, \mathrm{Al} ;---, \mathrm{Fe}$; - - $\mathrm{Cr} ; \cdots, \mathrm{S}$.

TABLE 1 The influence of metal organic chemical vapour deposition (MOCVD), pre- and post-oxidation on the weight gain due to sulphidation of the coating-substrate combination. Coating: $0.4 \mu \mathrm{m} \mathrm{Al}_{2} \mathrm{O}_{3}$ substrate: Incoloy $800 \mathrm{H}, 24 \mathrm{~h}$ sulphidation in $1 \% \mathrm{H}_{2} \mathrm{~S}-19 \% \mathrm{H}_{2}-80 \% \mathrm{Ar}$ at $600^{\circ} \mathrm{C}$

\begin{tabular}{ll}
\hline Treatment & $\begin{array}{l}\text { Weight gain } \\
\left(\mathrm{mg} \mathrm{cm}^{-2}\right)\end{array}$ \\
\hline None & $>3.00$ \\
$16 \mathrm{~h}$ at $850^{\circ} \mathrm{C}$ & $<0.5$ \\
MOCVD & $<0.1$ \\
$16 \mathrm{~h}$ at $850^{\circ} \mathrm{C}$ in & $<0.1$ \\
$\quad$ air before MOCVD & $<0.025$ \\
$16 \mathrm{~h}$ at $850^{\circ} \mathrm{C}$ in & \\
air after MOCVD & \\
\hline
\end{tabular}

Figure 10 shows a specimen treated in this way and sulphidized for $200 \mathrm{~h}$. An energy-dispersive $\mathrm{X}$-ray examination shows a very low sulphur content near a crack but no sulphur at all on the main parts of the coating (Fig. 11). The resulting weight gains are, in fact, mainly caused by inhomogeneities at the edges and the support hole.

\section{Conclusions}

It is possible to grow uniform $\mathrm{Al}_{2} \mathrm{O}_{3}$ thin films on stainless steel samples by metal organic CVD. Care has to be taken in order to carry out the deposition in the reaction-limited regime. Under the given conditions the deposition temperature must be lower than $420^{\circ} \mathrm{C}$.

Due to a proper deposition of these films a coating-substrate system exhibits an improved resistance to corrosion under the circumstances 
considered. The oxidation resistance may increase at least 5-10 times and the sulphidation resistance increases even more. Larger improvements can be obtained by depositing under conditions not causing cracks in the coating during oxidation or sulphidation. Therefore, the (thermo)mechanical properties of the coating are a very important object of further study.

Very large improvements (50-100 times) can be obtained by treating the specimen at $850{ }^{\circ} \mathrm{C}$ in air for $16 \mathrm{~h}$.

\section{Acknowledgments}

This research was partly supported by the Innovative Research Program on Technical Ceramics (IOP-TK) with the financial aid of the Dutch Ministry of Economic Affairs.

\section{References}

1 E. A. Polman, T. Fransen and P. J. Gellings, Mater. Sci. Eng., 88 (1987) 157.

2 M. J. Bennett, G. Dearnaly, M. R. Houlton, R. W. M. Hawes, P. D. Goode and M. A. Wilkins, Corros. Sci., 20 (1980) 73.

3 T. Fransen, P. J. Gellings, J. C. Fuggle, G. van der Laan, J.-M. Esteva and R. C. Karnatak, Appl. Surf. Sci., 20 (1985) 257.

4 M. J. Bennett, J. Vac. Sci. Technol. B, 2 (1984) 800.

5 P. Wong and M. Robbinson, J. Am. Ceram. Soc., 53 (1970) 617.

6 D. R. Messier and P. Wong, J. Electrochem. Soc., 118 (1971) 772 .

7 J. A. Aboaf, J. Electrochem. Soc., 114 (1967) 948.

$8 \mathrm{~K}$. F. Jensen and D. B. Graves, J. Electrochem. Soc., 130 (1983) 1950.

9 R. B. Bird, W. E. Steward and E. N. Lightfoot, Transport Phenomena, Wiley, New York, 1960, p. 658.

10 C. H. J. van de Brekel, J. Cryst. Growth., 43 (1978) 488.

11 W. L. Holstein, J. Electrochem. Soc., 137 (1988) 1788. 